\title{
Research Paper: Relapse Among Patients Referring to Residential Rehabilitation Centers for Drug Use Disorders in Iran and Its Related Factors
}

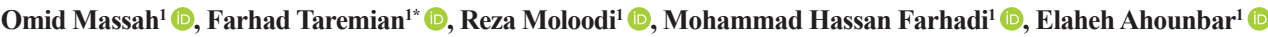

1. Substance Abuse and Dependence Research Center, University of Social Welfare and Rehabilitation Sciences, Tehran, Iran.

ditation: Massah O, Taremian F, Moloodi R, Farhadi MH, Ahounbar E. Relapse Among Patients Referring to Residential Rehabilitation Centers for Drug Use Disorders in Iran and Its Related Factors. Iranian Rehabilitation Journal. 2018; 16(2):139146. http://dx.doi.org/10.32598/irj.16.2.139

http://dx.doi.org/10.32598/irj.16.2.139

Article info:

Received: 17 Oct 2017

Accepted: 12 Feb 2018

\section{Keywords:}

Drug dependence, Residential treatment center, Drug use disorder, Relapse

\section{ABSTRACT}

Objectives: In this study, we aimed to determine the individual characteristics of clients who were referred to residential rehabilitation centers for drug use disorders and to determine their relapse-related factors.

Methods: This cross-sectional study was conducted on 576 patients who were referred to nine residential treatment centers for drug use disorders, chosen by the cluster sampling method. A self-constructed questionnaire to assess personal and addictive characteristics was applied. Data were analyzed using descriptive statistics and Independent t-test. Multiple regression models were applied to determine the factors affecting the time of relapse.

Results: The average interval between quitting drug use and relapse was found to be 4.7 months with a standard deviation of 4.1. Age and relapse were found to be correlated (0.193), but the correlation was not found to be statistically significant $(\mathrm{P}=0.12)$. There was significant correlation between occupational status $(\mathrm{P}=0.014)$ and number of attempts to quit drug use $(\mathrm{P}=0.019)$ with relapse. In addition, there were significant correlations between relapse time with injection history $(\mathrm{P}=0.035)$, victim's history $(\mathrm{P}=0.047)$, risky sexual behaviors $(\mathrm{P}=0.022)$, sexual dysfunction $(\mathrm{P}=0.019)$, having a consumer as a close friend $(\mathrm{P}=0.001)$, another drug user in family $(\mathrm{P}=0.001)$, compulsory treatment $(\mathrm{P}=0.033)$, and alcohol consumption $(\mathrm{P}=0.041$ ). There was no significant relationship between relapse with duration of addiction, type of abused drug, education, staying longer in centers, and marital status.

Discussion: There is a high chance of relapse in case of patients who seek treatment in residential rehabilitation centers for drug use disorders. Paying attention to the patients' social status and especially their occupation and connection with the treatment center after discharge reduces possibility of relapse. 


\section{Introduction}

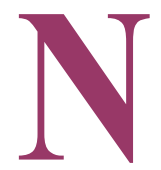

owadays, illicit drug use is a significant issue in most societies, with numerous personal and social consequences. Drug abuse coexists with physical, psychological, and behavioral disorders, as well as results in family conflicts. From the point of view of society, illicit drug use also leads to depreciated social and financial wealth, reduced moral and social security, undermined economy, and transmuted culture [1].

Despite appalling social attitude toward drug use, different classes of society are seriously involved with this growing issue. According to the previous statistics, in Iran, almost 2,808,000 people depend on some kind of illicit drugs. The growth rate of addiction is noticeably increasing, and there has been a rising trend for substance dependence in Iran. Newer drugs can cause far more dangerous personal and social harm with easier methods of consumption than that of opioids (such as opium and heroin) and have complicated prevention strategies and control over addiction [2].

Research findings suggest that factors such as personality traits, life style, social relationships, attitudes, beliefs, emotions, attachment styles, affections, and behaviors cultivated during an individual's development play a crucial role in substance dependence [3-5]. Hence, substance dependence has been considered as a disease rather than a crime in the new approach $[6,7]$. Relapse is an important problem in case of drug use disorders and addictive disorders [8, 9]. Different social, psychological, and biological factors affect the return to addiction [10] and in different treatment approaches, different factors are more effective [11].

In Iran, about two decades ago, residential treatment centers for drug use disorders have been established consequent to the expansion of new approach to addiction, which provides professional treatment services. In response to the increased demand, various private residential centers for the treatment of drug use disorders have been developed to facilitate faster recovery. Currently, more than thousand residential centers provide professional services in different cities of Iran. During more than a decade of activity, considerable financial and immaterial investments have been undertaken with respect to these treatment centers, and there is a great hope that these centers will deliver efficient services for those in the process of reducing drug use [12].
Some countries have studied the differences of residential treatment with that of other methods and their related factors to relapse [13], but in Iran, less attention has been paid with respect to relapse in patients among residential centers.

The knowledge regarding the characteristics of drugdependent population, relapse rate, and its related factors could be used efficiently in case of large-scale investment by a country that is combating drug abuse and its harmful social and individual consequences. Therefore, in this study, we aimed to determine the characteristics of clients who were referred to residential treatment centers for drug use disorders, their relapse, and repeated return to centers.

\section{Methods}

This cross-sectional study was conducted on 576 patients who were referred to residential treatment centers for drug use disorders in Iran. In 2015, all provinces of the country were geographically divided into nine parts. Samples were selected through cluster sampling method. In which geographic area was considered as a main cluster and from each of them, a province was selected and from each province two centers were selected. Study tool consisted of a 27-phrase self-constructed questionnaire evaluating personal and addictive characteristics of patients who visited treatment centers for drug use disorders. The questionnaire was compiled based on the related texts and resources and the content validity of it was reviewed by 10 experts and got approved after making the necessary changes and editions based on the study objectives, accordingly.

The first section consisted of six questions with respect to demographic and familial characteristics of the subjects including age, marital status (married, single, or divorced), and other substance-dependent members of the family (father, mother, brother, sister, etc.). The second section of the questionnaire covered addiction characteristics of individuals, such as type of currently used drug, types of previously used drugs, history of narcotics abuse, number of attempts to quit drugs at home or in clinics along with the date of each case, duration of stay in residential center, injection history, victim's history, risky sexual behaviors, sexual dysfunction, having a consumer as a close friend, and compulsory treatment.

To analyze the data, in addition to applying descriptive statistics, Independent t-test was used to compare relapse time between the two groups in terms of some demographic variables and analysis of variance test (ANOVA) was used to compare age and duration of abstinence 
among abusers of different types of drug. Multiple regression models were applied to determine effective factors on time of relapse. Data analysis and statistical tests were conducted by SPSS software.

\section{Results}

Table 1 shows the main categories of drug abuse and their percentage. As you can see, opium is more used than other drugs. Table 2 provides demographic data of the patients referred to residential treatment centers for drug use disorders. The mean $( \pm$ standard deviation (SD)) age of samples was found to be $35.5 \pm 9.65$ years. There was another substance-dependent member in the family, mostly a brother (36\%), among 47\% (271 persons) of patients studied. Mean $( \pm \mathrm{SD})$ year of substance dependence was found to be $11.4 \pm 8.8$, ranging between 2 and 33 years. Around $85.9 \%$ (495 individuals) of the patients had a history of at least one attempt to quit drugs. Reviewing past cases of quitting drugs showed that they attempted quitting at least once at home and thrice were referred to treatment centers for drug use disorders. In general, each individual tried quitting drugs four times on an average prior to their last attempt to quit drugs. Duration of addiction in people with histories of quitting drug and the ones with no such histories were 11.8 and 11.7 years, respectively, and therefore, was not statistically significant $(\mathrm{P}=0.96)$. Furthermore, 34\% (196

Table 1. Main categories of drug abuse and their percentage

\begin{tabular}{ccc}
\hline Type of Drug & Number of Users & Percentage \\
\hline Opium & 162 & 28.13 \\
Heroin & 144 & 25 \\
Methamphetamine & 132 & 22.92 \\
\hline Marijuana (Cannabis) & 86 & 14.93 \\
\hline Crack heroin & 52 & 9.02 \\
\hline
\end{tabular}

Table 2. Demographic data of patients referred to residential treatment centers for drug use disorders

\begin{tabular}{|c|c|c|c|}
\hline & Variable & Number of Samples & Percentage \\
\hline \multirow{5}{*}{ Education } & Illiterate & 231 & 40.10 \\
\hline & Primary school - ninth grade & 201 & 34.89 \\
\hline & & & \\
\hline & High school diploma & 115 & 19.96 \\
\hline & Higher than high school diploma & 29 & 5.05 \\
\hline \multirow{3}{*}{ Marital status } & Single & 156 & 27.9 \\
\hline & Married & 368 & 63.89 \\
\hline & Divorced & 52 & 9.02 \\
\hline \multirow{2}{*}{ Occupational status } & Employed & 316 & 54.87 \\
\hline & Unemployed & 260 & 45.13 \\
\hline \multirow{2}{*}{ History of quit attempts } & Positive & 507 & 88.02 \\
\hline & Negative & 69 & 11.98 \\
\hline \multirow{2}{*}{$\begin{array}{l}\text { History of addiction in family } \\
\text { members }\end{array}$} & Positive & 271 & 47.04 \\
\hline & Negative & 305 & 52.96 \\
\hline
\end{tabular}


people) had histories of quitting drugs at home and 3\% (17 persons) visited treatment centers for drug use disorders at their first attempt to quit drugs.

The average interval between quitting drug use and relapse was found to be 4.7 months $( \pm 4.1)$. Age and relapse were found to be correlated (0.193), but the correlation was not found to be statistically significant $(\mathrm{P}=0.12)$. Despite this nonsignificance, the existing correlation indicated that older individuals stay abstinent for a longer period of time than that of younger individuals. In terms of relapse, analysis of variance (ANOVA) showed no relationship between duration of abstinence and type of abused drug $(\mathrm{P}=0.457)$ and abusers of narcotics (i.e., opium, heroin, and crack heroin) do not differ from abusers of other drugs such as methamphetamine or cannabis.

Data analysis using multiple regression model revealed no significant relationship between duration of substance dependence, education, stay longer in residential center (camp), and marital status with the time when the individual relapses $(\mathrm{P}>0.05)$. There was a significant correlation between occupational status and time gap to relapse $(\mathrm{P}=0.014)$ as if employed individuals relapse later than unemployed individuals. However, the more quit attempts an individual had, the faster they relapsed; this means that past histories of drug use disorder treatment is positively correlated with time of relapse $(\mathrm{P}=0.019)$.

Moreover, there were significant correlations between relapse time with injection history $(\mathrm{P}=0.035)$, victim's history $(\mathrm{P}=0.047)$, risky sexual behaviors $(\mathrm{P}=0.022)$, sexual dysfunction $(\mathrm{P}=0.019)$, having a consumer as close friend $(\mathrm{P}=0.001)$, another drug user in family $(\mathrm{P}=0.001)$, compulsory treatment $(\mathrm{P}=0.033)$, and alcohol consumption $(\mathrm{P}=0.041)$.

\section{Discussion}

This study was conducted to determine demographic characteristics of patients who were referred to residential treatment centers for drug use disorders and to understand the underlying factors that affect relapse after a period of abstinence due to undergoing treatment from treatment centers for drug use disorders in Iran. The mean age of patients was found to be 37.5 years which is higher than the reported value in Delavarpoor's study. Around $40.1 \%$ of the individuals were found to be illiterate and $34.9 \%$ were found to be educated up to the 9th grade. This finding is in consistent with other studies that reported majority of the patients as illiterate or loweducated $[10,14,15]$. However there was no significant relation between education and relapse, which is in contrast to the results of Brorson's study [10].

There was no significant correlation between age and time gap to relapse. This is in-line with the findings of some other studies [16, 17]. Some studies found a significant relationship between age and relapse, and relapse was reported as lower in older addicts than that of younger addicts $[10,18,19]$.

Marital status was found to be unrelated to relapse, for example in Oji's study [17], whereas Rollins reported a significant relationship in his study [19].

Interval between abstinence and relapse was found to be 4.7 months, which was found to be longer than that of other studies which reported a period of 1-3 months of abstinence [20, 21]. Individuals in this study attempted to quit drugs four times on an average which indicates a high rate of relapse among them, considering the average 12 years of substance dependence reported by them. Behravan reported a high incidence of lapse as the reason for high rate of relapse [18].

Other studies also have reported that at least $60-70 \%$ of the addicts who attempted to quit drugs through residential centers relapsed within 6-12 months [22, 23] and after 12-18 months, this estimate will increase [24]. Another study has reported $75-90 \%$ of relapse rate [25]. In addition, Norco et al, reported a $66 \%$ relapse rate after abstinence within a period of 6 months [26].

In this study, $86 \%$ of the individuals had at least one history of quit attempt, which is a higher than the value reported by Parvizi (54\%) [27]. Presence of one addict member in the family is known as one of the influencing factors on people's tendency to drug abuse. In this study, $47 \%$ of the participants had at least one drug-dependent member in the family. In the study by Tavakoli et al, $37.5 \%$ of the substance dependents who seek treatment reported presence of at least one addicted member in their family [28]. In addition, having a consumer as a close friend or another drug user in family was found to be significantly related to increased risk of relapse. This finding has also been reported in another study [24]. Many studies suggested environmental and interpersonal variables as the cause of relapse and mentioned factors such as losing social and familial status, society pressure to abuse drugs, such as living with a drug abuser or passing through stamp grounds, as the main reasons of relapse [23, 29-32].

In this study, $34 \%$ of the participants had a history of home-based drug quit and only $3 \%$ of the sample popula- 
tion attempted their first quit at a clinic. In other words, most addicts prefer home-based treatment at least for their first attempt to quit drugs. This is in-line with the findings of Ziaaddini et al.'s study that reported $65 \%$ of the study population tended to home-based drug quit [33].

Regression analysis indicates that unemployment is one of the effective factors of relapse. Various studies have shown a significant relationship between unemployment and substance dependence and that probability of addiction is higher among unoccupied population $[19,34]$. Although there was a direct and significant relationship between employment and relapse and the patients who were employed were also more likely to relapse than those who were unemployed [24]. Lack of permanent employment was also known as a factor of tendency toward addiction [35].

Frequency of past attempts to quit drugs is another important factor of relapse. This finding is in-line with Greenwood's study which reported that the number of prior drug use treatment attempts is significantly associated with relapse risk [24]. One of the primary reasons of relapse among patients who have been treated is lack of follow-up or supervision after they get discharged; In fact, this matter was pointed out in some studies as well [36].

In this study, there was no relationship between duration of abstinence and type of abused drug, but in other studies rate of relapse has been found to be significantly different between consumers of different types of drug [10]. This difference may be related to the difference in common drugs in different countries.

Our findings showed no significant relationship between staying longer in residential center (camp) and reducing the risk of relapse. In fact, staying longer in the center was found to have no effect on reducing relapse in short and medium term residential centers. Although other studies have shown different results, most of them are related to long-term centers and Therapeutic Community (TC) programs $[37,38]$.

Other findings of this study showed significant correlations between relapse time with injection history, victim's history, and risky behaviors. These findings are in-line with other studies [10, 24]. As previously shown, personality traits (such as sensation seeking) are related to the tendency to drug use $[39,40]$; based on the findings of this research, it seems to be related to relapse. Furthermore, in this study, there was a significant relationship between relapse time and compulsory treatment. According to previous studies, patient motivation seems to be an important factor in the success of treatment [17].

This study has several limitations. First, the study was limited to men. Therefore, the study findings may not be generalizable to women. Second, the study was limited to residential treatment centers and abstinent-based self-help groups who were referred to residential centers. Therefore, the study findings may not be generalizable to other approaches of drug use disorder treatment such as medication-assisted treatment. However, this study is among few studies that investigated the relapse among patients who were referred to residential treatment centers. Future studies should consider the relapse and its affecting factors and gender differences among both men and women with respect to all types of addiction treatment programs.

\section{Conclusion}

There is a high chance of relapse among patients who seek treatment in residential treatment centers for drug use disorders and there are many factors affecting it. Paying attention to psychosocial status and especially their connection with treatment center and therapist after discharge reduces possibility of relapse.

\section{Ethical Considerations}

\section{Compliance with ethical guidelines}

The study was approved by the Ethic Committee of the University of Social Welfare and Rehabilitation Sciences. All participants signed consent forms and were informed that participation was confidential and voluntary. Also they were assured that the lack of participants would not have any impact on their treatment.

\section{Funding}

This research did not receive any specific grant from funding agencies in the public, commercial, or not-forprofit sectors.

\section{Conflict of interest}

The authors declare no conflicts of interest.

\section{Acknowledgements}

Authors highly appreciate the efforts of all colleagues from all the provinces who collaborated in collecting the questionnaires. 


\section{References}

[1] United Nations office on Drugs and Crime. World Drug Report. Vienna: United Nations office on Drugs and Crime; 2015.

[2] Welfare Organization of Iran. [House hold national survey on illicit drug use in Iran 2015 (Persian)]. Tehran: Welfare Organization of Iran; 2017.

[3] Kotov R, Gamez W, Schmidt F, Watson D. Linking "big" personality traits to anxiety, depressive, and substance use disorders: A meta-analysis. Psychological Bulletin. 2010; 136(5):768.

[4] Sher KJ, Bartholow BD, Wood MD. Personality and substance use disorders: A prospective study. Journal of Consulting and Clinical Psychology. 2000; 68(5):818. [DOI:10.1037/0022006X.68.5.818] [PMID]

[5] Padgett DK, Henwood B, Abrams C, Drake RE. Social relationships among persons who have experienced serious mental illness, substance abuse, and homelessness: Implications for recovery. American Journal of Orthopsychiatry. 2008, 78(3):333-9. [DOI:10.1037/a0014155] [PMID]

[6] White W. Addiction disease concept: Advocates and critics. The Counselor. 2001; 2(1):42-6.

[7] McLellan AT, Lewis DC, O'brien CP, Kleber HD. Drug dependence, a chronic medical illness: Implications for treatment, insurance, and outcomes evaluation. JAMA. 2000 284(13):1689-95. [DOI:10.1001/jama.284.13.1689] [PMID]

[8] Litman GK. Alcoholism survival. In Miller WR, Heather N (eds), Treating addictive behaviors. Berlin: Springer; 1986. [DOI:10.1007/978-1-4613-2191-0_20]

[9] Hunt WA, Barnett LW, Branch LG. Relapse rates in addiction programs. Journal of Clinical Psychology. 1971; 27(4):4556. [DOI:10.1002/1097-4679(197110)27:43.0.CO; 2-R]

[10] Brorson HH, Ajo Arnevik E, Rand-Hendriksen K, Duckert F. Drop-out from addiction treatment: A systematic review of risk factors. Clinical Psychology Review. 2013; 33(8):1010-24. [DOI:10.1016/j.cpr.2013.07.007] [PMID]

[11] Bukten A, Skurtveit S, Waal H, Clausen T. Factors associated with dropout among patients in Opioid Maintenance Treatment (OMT) and predictors of re-entry: A national registry-based study. Addictive Behaviors. 2014; 39(10):1504-9. [DOI:10.1016/j.addbeh.2014.05.007] [PMID]

[12] Roshanpajouh M. [There are more than thousand residential centers for drug addicts in the country (Persian)]. Islamic Republic News Agency. 2015 April 26

[13] Stahler GJ, Mennis J, DuCette JP. Residential and outpatient treatment completion for substance use disorders in the U.S.: Moderation analysis by demographics and drug of choice. Addictive Behaviors. 2016; 58(Suppl C):129-35. [DOI:10.1016/j.addbeh.2016.02.030] [PMID]

[14] Delavarpoor MA, Soltani M, Hosseinchari M. Prediction of recovery or relapse from substance abuse based on the emotional intelligence and religious coping. Iranian Journal of Psychiatry and Clinical Psychology. 2008; 14(3):307-15.

[15] Abassi A, Taziki S, Moradi A. The prototype of drug misabused of opioids in the self-introduced addicts in Gorgan
(North-East of Iran). Journal of Gorgan University of Medical Sciences. 2006; 8(17):22-7.

[16] Martin T, Josiah-Martin J, Kosakoski J, Norton K, Sinnott $\mathrm{T}$. A comparison of patients relapsing to addictive drug use with non-relapsing patients following residential addiction treatment in Antigua. West Indian Medical Journal. 2005; 54(3):196-201. [DOI:10.1590/S0043-31442005000300008] [PMID]

[17] Oji A, Sohrabi F, Jomehri F, Massah O, Molavi N. Role of motivation for behavior change in treatment retention amongst a group of illicit drug users: A study from Iran. Iranian Journal of Psychiatry and Behavioral Sciences. 2016 (In Press). [DOI: 10.5812/ijpbs.8325]

[18] Behravan H, Miranvari S. A sociological analysis of drug addict's relapse in the therapeutic community of Mashhad, Iran. Iranian Journal of Scocial Problems. 2010; 1(1):45-78.

[19] Rollins AL, O'Neill SJ, Davis KE, Devitt TS. Special section on relapse prevention: Substance abuse relapse and factors associated with relapse in an inner-city sample of patients with dual diagnoses. Psychiatric Services. 2005; 56(10):127481. [DOI:10.1176/appi.ps.56.10.1274] [PMID]

[20] Jandaghi G, Alii V. Study of the effect factors on quit addiction among the self-introduced addicts in tyhe South of Tehran in 1999. Hakim. 2002; 4(4):291-3.

[21] Amani F, Sadegie Ahari S, Mohammadi S, Azami A. The trend in substance abuse among addicts referred to withdrawal centers, 1998-2003. Journal of Ardabil University of Medical Sciences. 2005; 5(3):220-4

[22] Gossop M, Green L, Phillips G, Bradley B. Lapse, relapse and survival among opiate addicts after treatment: A prospective follow-up study. The British Journal of Psychiatry. 1989; 154(3):348-53. [DOI:10.1192/bjp.154.3.348] [PMID]

[23] Gossop M, Stewart D, Browne N, Marsden J. Factors associated with abstinence, lapse or relapse to heroin use after residential treatment: Protective effect of coping responses. Addiction. 2002; 97(10):1259-67. [DOI:10.1046/j.13600443.2002.00227.x] [PMID]

[24] Greenwood GL, Woods WJ, Guydish J, Bein E. Relapse outcomes in a randomized trial of residential and day drug abuse treatment. Journal of Substance Abuse Treatment. 2001; 20(1):15-23. [DOI:10.1016/S0740-5472(00)00147-1]

[25] Milkman H, Weiner SE, Sunderwirth S. Addiction relapse. Advances in Alcohol \& Substance Abuse. 1984; 3(1-2):119-34 [DOI:10.1300/J251v03n01_09]

[26] Nurco DN, Kinlock TW, O'Grady KE, Hanlon TE. Differential contributions of family and peer factors to the etiology of narcotic addiction. Drug \& Alcohol Dependence. 1998; 51(3):229-37. [DOI:10.1016/S0376-8716(98)00041-6]

[27] Parvizi D, Rahgozar M, Vameghi R, Forughan M. Influencing factors on client satisfaction in governmental addiction treatment centers and comparison with private centers in Kordestan province in year 1383 (2004). Hakim. 2008; 11(1):48-53

[28] Tavakoli Ghouchani H, Armat M, Mortazavi H. Factors related to embarking on addiction cessation in clients referring to Bojnord behzisti addiction cessation clinic from 2000 until 2001. Journal of Zanjan University of Medical Sciences. 2002; 10(38):32-7. 
[29] Gossop M, Marsden J, Stewart D, Rolfe A. Treatment retention and 1 year outcomes for residential programmes in England. Drug and Alcohol Dependence. 1999; 57(2):89-98 [DOI:10.1016/S0376-8716(99)00086-1]

[30] Lowinson JH. Lowinson and Ruiz's substance abuse: A comprehensive textbook. Philadelphia: Lippincott Williams \& Wilkins; 2011.

[31] Sinha R. How does stress increase risk of drug abuse and relapse. Psychopharmacology. 2001; 158(4):343-59. [DOI:10.1007/s002130100917] [PMID]

[32] Domino KB, Hornbein TF, Polissar NL, Renner G, Johnson J, Alberti S, et al. Risk factors for relapse in health care professionals with substance use disorders. JAMA. 2005; 293(12):1453-60. [DOI:10.1001/jama.293.12.1453] [PMID]

[33] Ziaaddini S, Zarezadeh A, Heshmati F. The Prevalence Rate of Substance Abuse and Addiction and Some Relevant Factors among Junior and Senior High School Students in Kerman City (2000-2001). Journal of Kerman University of Medical Sciences. 2006; 13(2):84-94.

[34] DinMohammadi M, Amini K, Yazdankhah M. Survey of social and environmental factors related to the relapse of addiction in volunteer addicted individuals in welfare organization of Zanjan. Zanjan University of Medical Sciences Journal. 2007; 15(59):85-94.

[35] Asayesh H, Qorbani M, Salary H, Mansorian M, Safari R. The relation between individual and familial characteristics with substance abuse tendency. Journal of Gorgan University of Medical Sciences. 2011; 12(4):91-9.

[36] Zeinali A, Vahdat R, Garadingeh K. The relationship between parenting style and addiction susceptibility in children. Journal of Family Research. 2010; 6(23):335-52.

[37] Malivert M, Fatséas M, Denis C, Langlois E, Auriacombe M. Effectiveness of therapeutic communities: A systematic review. European Addiction Research. 2012; 18(1):1-11. [DOI:10.1159/000331007] [PMID]

[38] McCusker J, Stoddard A, Frost R, Zorn M. Planned versus actual duration of drug abuse treatment: Reconciling observational and experimental evidence. The Journal of Nervous and Mental Disease. 1996; 184(8):482-9. [DOI:10.1097/00005053199608000-00005] [PMID]

[39] Karami Z, Pirkhaefi A, Kowsarnia A, Massah O, Farhoodian A. Comparison of personality traits based on Temperament and Character Inventory (TCI) in opiate and stimulant abusers. Journal of Rehabilitation. 2014; 14(5):83-90.

[40] Massah O, HoseinSabet F, Doostian Y, A'zami Y, Farhoudian A. The role of sensation-seeking and coping strategies in predicting addiction potential among students. Practice in Clinical Psychology. 2014; 2(3):173-80. 
